The Impact of Clinical and Genetic Findings on The Management of Young Brugada Syndrome Patients

Antoine ANDORIN MD, Elijah R. BEHR MA, MBBS, MD, FRCP, Isabelle DENJOY MD, Lia CROTTI MD, PhD, Federica DAGRADI MD, Laurence JESEL MD, Frederic SACHER MD, Bertrand PETIT MD, Philippe MABO MD, Alice MALTRET MD, Leonie C.H. WONG MD, Bruno DEGAND MD, Géraldine BERTAUX MD, Philippe

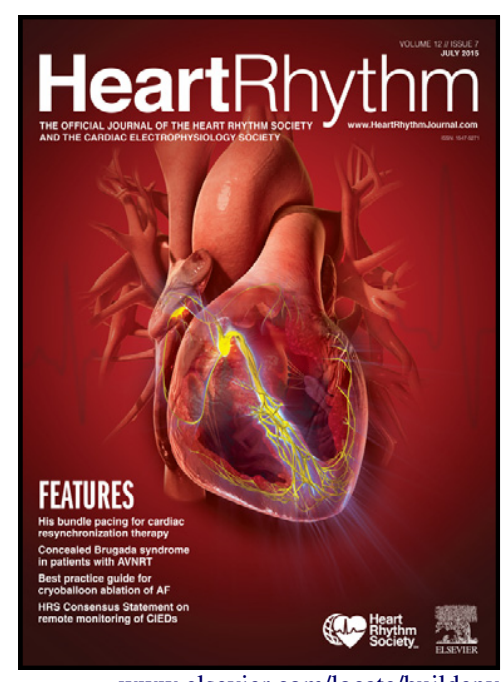
MAURY MD, Yves DULAC MD, Béatrice DELASALLE MS, Jean-Baptiste GOURRAUD MD, PhD, Dominique BABUTY MD, PhD, Nico A. BLOM MD, PhD, Peter J. SCHWARTZ MD, Arthur A. WILDE MD, PhD, Vincent PROBST MD, PhD

PII: S1547-5271(16)00182-X

DOI: http://dx.doi.org/10.1016/j.hrthm.2016.02.013

Reference: $\quad$ HRTHM6626

To appear in: Heart Rhythm

Cite this article as: Antoine ANDORIN MD, Elijah R. BEHR MA, MBBS, MD, FRCP, Isabelle DENJOY MD, Lia CROTTI MD, PhD, Federica DAGRADI MD, Laurence JESEL MD, Frederic SACHER MD, Bertrand PETIT MD, Philippe MABO MD, Alice MALTRET MD, Leonie C.H. WONG MD, Bruno DEGAND MD, Géraldine BERTAUX MD, Philippe MAURY MD, Yves DULAC MD, Béatrice DELASALLE MS, Jean-Baptiste GOURRAUD MD, PhD, Dominique BABUTY MD, PhD, Nico A. BLOM MD, PhD, Peter J. SCHWARTZ MD, Arthur A. WILDE MD, PhD, Vincent PROBST MD, PhD, The Impact of Clinical and Genetic Findings on The Management of Young Brugada Syndrome Patients, Heart Rhythm, http://dx.doi.org/10.1016/j. hrthm.2016.02.013

This is a PDF file of an unedited manuscript that has been accepted for publication. As a service to our customers we are providing this early version of the manuscript. The manuscript will undergo copyediting, typesetting, and review of the resulting galley proof before it is published in its final citable form. Please note that during the production process 


\section{The impact of clinical and genetic findings on the management of young Brugada}

\section{Syndrome patients}

Antoine ANDORIN ${ }^{1}$, MD, Elijah R. BEHR ${ }^{2}$, MA, MBBS, MD, FRCP, Isabelle DENJOY ${ }^{3}$, MD, Lia CROTTI ${ }^{4,5}, \mathrm{MD}, \mathrm{PhD}$, Federica DAGRADI $^{4}, \mathrm{MD}$, Laurence JESEL ${ }^{6}$, MD, Frederic

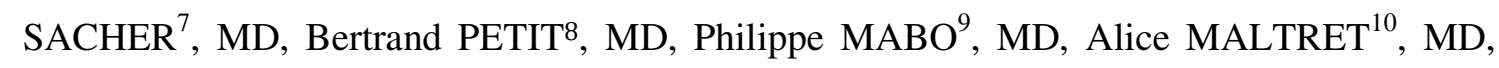
Leonie C. H. WONG ${ }^{2}$, MD, Bruno DEGAND ${ }^{11}$, MD, Géraldine BERTAUX ${ }^{12}$, MD, Philippe MAURY ${ }^{13}$, MD, Yves DULAC ${ }^{13}$, MD, Béatrice DELASALLE ${ }^{1}$, MS, Jean-Baptiste GOURRAUD ${ }^{1}, \mathrm{MD}, \mathrm{PhD}$ Dominique BABUTY14 MD, PhD, Nico A. BLOM ${ }^{15,16}, \mathrm{MD}, \mathrm{PhD}$, Peter J. SCHWARTZ ${ }^{4}, \mathrm{MD}$, Arthur A. WILDE ${ }^{17,18}, \mathrm{MD}, \mathrm{PhD}$ and Vincent PROBST ${ }^{1}, \mathrm{MD}$, $\mathrm{PhD}$.

${ }^{1}$ CHU Nantes, Institut du Thorax, Nantes, France

${ }^{2}$ Saint George's University of London, London, United Kingdom

${ }^{3}$ AP-HP, Hôpital Bichat, Paris, France

${ }^{4}$ Center for Cardiac Arrhythmias of Genetic Origin, IRCCS Istituto Auxologico Italiano, Milan, Italy

${ }^{5}$ University of Pavia, Department of Molecular Medicine, Pavia, Italy

${ }^{6}$ CHU Strasbourg, Strasbourg, France

${ }^{7}$ CHU Bordeaux, Hôpital Cardiologique du Haut Lévêque, Bordeaux, France,

${ }^{8}$ CHR-GHSR La Réunion, Saint Pierre, France

${ }^{9}$ CHU Rennes, Hôpital Pontchaillou, Rennes, France

${ }^{10}$ AP-HP, Hôpital Necker-Enfants Malades, Paris, France

${ }^{11}$ CHU Poitiers, Poitiers, France

${ }^{12}$ CHU Dijon, Dijon, France 
${ }^{13}$ Hôpital des Enfants, Toulouse, France

${ }^{14}$ CHU Tours, Hôpital Trousseau, Tours, France

${ }^{15}$ Leiden University Medical Centre, Pediatric cardiology, Leiden, Netherlands,

16 Academic Medical Centre, Heart Centre, Dept of Pediatric cardiology, University of Amsterdam, Amsterdam, Netherlands.

17 Academic Medical Centre, Heart Centre, Dept of Clinical and Experimental cardiology, University of Amsterdam, Amsterdam, Netherlands

${ }^{18}$ Princess Al-Jawhara Al-Brahim Centre of Excellence in Research of Hereditary Disorders, Jeddah, Kingdom of Saudi Arabia

Short Title: Brugada Syndrome in the young: New data Address for Correspondence: Antoine ANDORIN, Service de Cardiologie, CHU de Nantes Hôpital Nord -Laennec, Bvd Jacques Monod, 44093 Nantes Cedex, France ; email : antoine.andorin@gmail.com ; tel +33 240165009; fax +33 240165024

Conflict of Interest : none

\section{Abstract}

Backgroung: Brugada Syndrome (BrS) is an arrhythmogenic disease associated with sudden cardiac death (SCD) which seldom manifests or is recognized in childhood.

Objective: To describe the clinical presentation of pediatric $\mathrm{BrS}$ to identify prognostic factors for risk stratification, and propose a data-based approach management.

Methods: We studied 106 patients, under 19 years of age at diagnosis of $\mathrm{BrS}$ from 16 European hospitals.

Results: At diagnosis, $\mathrm{BrS}$ was spontaneous $(\mathrm{n}=36)$ or drug-induced $(\mathrm{n}=70)$. Mean age was 11.1 \pm 5.7 years and most patients were asymptomatic [family screening $(n=67)$, incidental $(\mathrm{n}=13)$ ] while 15 had experienced syncope, 6 aborted SCD or symptomatic ventricular 
tachycardia and 5 others symptoms. During follow-up (median: 54 months), 10 patients had life-threatening arrhythmias (LTA) including 3 deaths. Six experienced syncope and 4 SVT. Fever triggered $27 \%$ of LTA events. An ICD was implanted in 22 with major adverse events in $41 \%$. Of the 11 patients treated with hydroquinidine, 8 remained asymptomatic. Genetic testing was performed in 75 patients and SCN5A rare variants were identified in $58 ; 15$ out of $32(47 \%)$ tested probands were genotype positive. Nine out of the 10 patients with LTA underwent genetic testing and all were genotype positive whereas the 17 SCN5A negative patients remained asymptomatic. Spontaneous BrS type 1 ECG $(p=0.005)$ and symptoms at diagnosis $(p=0.001)$ were predictors of LTA. Time to the first LTA event was shorter in patients with both symptoms at diagnosis and spontaneous BrS type 1 ECG pattern $(p=0.006)$.

Conclusions: Spontaneous type 1 ECG and symptoms at diagnosis are predictors of LTA events in the young affected by BrS. The management of BrS should become age-specific and prevention of SCD may involve genetic testing, aggressive use of anti-pyretics and quinidine with risk-specific consideration for the ICD.

\section{Keys Words}

Brugada syndrome; Pediatrics; Arrhythmia; Death sudden; Genetics

\section{Abbreviations List}

aSCD: aborted Sudden Cardiac Death

BrS: Brugada Syndrome

DNA: Deoxyribonucleic Acid

ECG: Electrocardiogram

EPS: Electrophysiological Study

HR: Hazard Ratio 
LTA: Life Threatening Arrhythmias

ICD: Implantable Cardioverter Defibrillator

NSVT: Non-Sustained Ventricular Tachycardia

PCR: Polymerase Chain Reaction

SCD: Sudden Cardiac Death

SVT: Supra Ventricular Tachycardia

VF: Ventricular Fibrillation

VT: Ventricular Tachycardia

\section{Introduction}

The Brugada Syndrome $(\mathrm{BrS})$ is an arrhythmogenic disease ${ }^{1}$, with a heterogeneous genetic background $^{2-5}$, usually diagnosed during adulthood. Spontaneous type 1 ECG pattern and symptoms are predictive risk factors for life-threatening arrhythmias (LTA) in adults ${ }^{2}$ but, given the rarity of $\mathrm{BrS}$ in the pediatric population, risk stratification in the young is difficult.

In a Japanese study ${ }^{6}$ screening elementary school children, only $0.02 \%$ of 22,000 displayed a Brugada type related ECG with only one case of spontaneous type 1 ECG pattern. The largest pediatric BrS population studied so far included 30 European children and suggested that fever, symptoms and spontaneous type 1 ECG pattern were associated with LTA $^{7}$. Drug-induced BrS in children has been reported ${ }^{8}$. In the largest series of $\mathrm{BrS}$ in adulthood $^{2}$, very few patients were below age 20 .

Our aim was to describe the clinical presentation of BrS below age 19, to identify prognostic factors useful to improve risk stratification, and to propose a data-based approach to management of this specific population. 


\section{Methods}

\section{Clinical Data}

Data on 106 patients below age 19 were collected from 16 European tertiary centers; 29 of them had been described originally in $2007^{7}$. Inclusion required a type 1 Brugada ECG pattern either spontaneously or after challenge with a sodium channel blocker (ajmaline or flecainide). Patients displaying only fever-induced Brugada type 1 ECG pattern were included in the spontaneous group. The type 1 ECG pattern was defined according to consensus guidelines as coved ST-elevation $\geq 0.2 \mathrm{mV}$ at its peak in at least one right precordial leads ( $\mathrm{V}_{1}$ to $\mathrm{V}_{3}$ in the $2^{\text {nd }}, 3^{\text {rd }}$ or $4^{\text {th }}$ intercostal spaces $)^{9,10}$.

Recorded data included: family history; past medical history; follow-up data from hospitalization reports, specialist and general cardiology clinical letters; and direct follow-up contact with patients. Syncope was considered of arrhythmic origin when a sudden loss of consciousness occurs without any other explanation.

Twelve-lead ECGs at baseline and, if needed, during drug-challenge, were performed according to the guidelines ${ }^{10}$. The 12-lead ECGs were first analyzed by an expert cardiologist in the referring hospital. ECG parameters were then collected at baseline and during drug challenge. Either intravenous ajmaline $(1 \mathrm{mg} / \mathrm{kg}$ body weight) or flecainide $(2 \mathrm{mg} / \mathrm{kg}$ body weight) were used depending on drug availability at the participating centers.

A baseline electrophysiological study (EPS) was performed in 22 patients at the clinical judgment of the expert cardiologist. A maximum of three ventricular extrastimuli with a minimum coupling interval of $200 \mathrm{~ms}$ were delivered from at least one right ventricular site unless VF and/or sustained VT were induced at an earlier stage.

At diagnosis, patients were considered symptomatic if they had experienced aborted SCD (aSCD), ventricular arrhythmias [non-sustained VT (NSVT), VT or VF] or syncope. 
During follow-up, patients were considered to have a LTA event if sudden death, documented VT or VF occurred or if an appropriate ICD shock was documented.

\section{Genetic Analysis}

Genetic testing was conducted according to guidelines and was approved by local ethics committees for research or regular clinical purposes. Informed written consent was obtained either from the parents or the patient (if above age 18). Genomic DNA was extracted from peripheral blood leukocytes using standard protocols. All exons of SCN5A were amplified by PCR. PCR products were screened for an SCN5A mutation using denaturing high-performance liquid chromatography and/or direct DNA sequencing. In probands, all exons of SCN5A were screened whereas only the specific exon was sequenced if a rare variant had been identified previously in the family.

\section{Statistical Analysis}

Data were analyzed with SAS packages (SAS Institute Inc., Cary, NC). The Chi2 or Fisher exact tests were used to compare categorical variables. The t-test, Mann-Whitney, Kruskall Wallis tests were performed to test for differences in continuous parameters. ECG baseline data were corrected for age using linear regression model. Mean data were presented with standard deviation. Time data were presented with median $\left[1^{\text {st }}-3^{\text {rd }}\right.$ quartile $]$. Time from diagnosis to the first event was analyzed with Cox proportional hazards model. Hazards ratios (HR), confidence intervals (CI) and p-values were calculated in univariate analysis. Log-rank p-value was used if Cox model was not relevant. Multivariate analysis was adjusted on variable with p-value $<0.15$ in univariate analysis using Cox model. Survival curves were plotted by the Kaplan Meier method. A p-value $<0.05$ was considered statistically significant.

The authors had full access to and take full responsibility for the integrity of the data. All authors have read and agree to the manuscript as written. 


\section{Results}

\section{Population}

A total of 106 patients from 91 families were enrolled. The mean age at diagnosis was 11.1 \pm 5.7 years with a median $\left[1^{\text {st }}-3^{\text {rd }}\right.$ quartiles] follow-up of 54 [15-99] months which was longer $(117$ [87-142]; $p<0.0001)$ among the 29 children described in $2007^{7}$. Forty-six $(43 \%)$ had a familial history of SCD. Sixty-seven children were diagnosed below 15 years of age, including 35 below age 8 . Fifty-eight (55\%) were male. No gender difference was observed under 15 years of age (sex ratio=1.03; 34M/33F) but there was a trend for males to be more common above age 15 (sex ratio=1.60; $24 \mathrm{M} / 15 \mathrm{~F}[p=0.32])$.

Symptoms (supplemental material; Table 2): Twenty-one (20\%) patients were considered symptomatic at diagnosis: $15(14 \%)$ syncope; 4 aSCD; and 2 with VT. They were predominantly male (sex ratio=2.5). Five out of the 6 patients with aSCD or VT were under 5 years of age. Most patients were completely asymptomatic at diagnosis (67 [63\%] diagnosed during familial screening and 13 [12\%] incidentally). In addition, 2 patients who presented with supra-ventricular tachycardia (SVT) and 3 who experienced subjective symptoms (presyncope or palpitations) were considered asymptomatic at diagnosis for the purposes of our survival analyses.

ECG findings at diagnosis (supplemental material; Table 3): Thirty-six (34\%) patients presented with a spontaneous type 1 ECG pattern, of whom 14 (39\%) were symptomatic at diagnosis. Among these 36 patients, 7 displayed the type 1 ECG pattern only during a fever episode (Figure 1). The $70(66 \%)$ remaining patients presented with a type 1 pattern after provocation testing, of whom only 7 (10\%) were symptomatic at diagnosis. Males were more common in the spontaneous group $($ sex ratio $=2.6)$ whereas females were more common in the drug-induced group (sex ratio $=0.84[p=0.013]$ ). A spontaneous type 1 ECG pattern was significantly associated with male gender $(p=0.013)$ and symptoms at diagnosis $(p=0.0007)$. 
Genetics (Table 1): Seventy-five patients, belonging to 62 families, underwent SCN5A analysis. Thirty-two (43\%) were pediatric probands in whom all exons were tested: fifteen (47\%) tested positive. In 43 patients, direct sequencing was performed to detect the SCN5A mutation identified in the family. Overall 58/75 (77\%) were genotype positive (Supplemental material Table 1).

\section{Drug Challenge/EPS}

Drug challenges were performed in $70(66 \%)$ patients with ajmaline $(n=42)$ or flecainide ( $n=27$; unknown=1). Median ages at challenges were $14.3 \pm 3.7$ years for ajmaline and $13.4 \pm 4.5$ years for flecainide $(p=0.38)$. Two patients $(15.6$ and 16.7 years of age both SCN5A positive) developed NSVT for which no specific therapy was needed. No other adverse events were observed. ECG parameters at baseline, before and during drug challenge are summarized in Supplemental material; Table 4. EPS were performed in $22(21 \%)$ patients, nine of whom were symptomatic at diagnosis, and were reported as "positive" or VF inducible in $9(41 \%)$.

\section{Treatment}

An ICD was implanted in $22(21 \%)$ patients, of whom 18 received an endocardial ICD and 3 a system with an epicardial ventricular lead and a subcutaneous or intercostal coil. Eighteen ICDs were implanted as primary prevention whilst four patients were implanted after an aSCD or VT. Four pacemakers were implanted in SCN5A positive patients with symptomatic sinus node dysfunction.

Hydroquinidine was started in $11(10 \%)$ patients: 9 (8\%) with a spontaneous type 1 ECG pattern; and 8 following arrhythmic events. Blood concentrations of quinidine were only available in 3 patients, and in the therapeutic range as defined by the local laboratory. No side effects were reported for hydroquinidine. 


\section{Follow-up}

During a median follow-up of 54 [15-99] months 10 (9\%) patients had 15 LTA events. Fever was associated with $4(27 \%)$ of these events. Three patients died, 5 suffered VT and 2 both VT and VF. The mean age at diagnosis was $6.5 \pm 7.0$ years with a median followup of 42 [6-73] months (Table 2). Two had a drug-induced type 1 ECG pattern at diagnosis. Seven $(70 \%)$ were symptomatic at diagnosis $[\operatorname{aSCD}(n=3)$, syncope $(n=3)$ and VT $(n=1)]$. Nine (90\%) carried a SCN5A mutation.

A LTA during follow-up was experienced by 2 out of 9 (22\%) patients with a positive EPS, and by 1 of $13(8 \%)$ patients who had a negative EPS $(p=0.85)$. Two (11\%) from the 18 primary prevention ICD patients had appropriate ICD shocks. Eight (73\%) of the 11 patients receiving hydroquinidine remained free from LTA after initiation of therapy.

Another $6(6 \%)$ were syncopal without documented arrhythmia. Four (4\%) had SVT: two atrial flutter treated by catheter ablation and two atrial tachycardia. A flow-chart of clinical presentation and follow-up is presented in Figure 2 and a clinical description of LTA events during follow-up can be found in supplementary data.

\section{ICD complications}

Serious ICD-related complications occurred in $9(41 \%)$ of the 22 patients including lead failures $(n=4)$, inappropriate shocks $(n=4)$, endocarditis with re-implantation $(n=2)$ and hemothorax $(n=1)$. Two patients had both lead failure and inappropriate shocks or endocarditis. All complications were related to endocardial devices except the hemothorax, which appeared in the early post-operative period after epicardial ventricular lead implantation. 


\section{Predictive factors for LTA}

Nine of the 10 patients who experienced LTA were SCN5A carriers (Table 3), the remaining patient having not undergone genetic screening. LTA did not occur in the 17 genotype-negative patients.

In a univariate analysis, a spontaneous type 1 ECG pattern (HR=9.1; CI [1.9-42.96]; $p=0.005)$ and symptoms at diagnosis (HR=9.65; CI [2.48-37.49]; $p=0.001)$ were predictive of a shorter time to first LTA event whereas a family history of $\operatorname{SCD}(p=0.28)$, gender $(p=0.72)$ and positive $S C N 5 A(p=0.08)$ genotype were not (Table 3). Due to the low number of patients undergoing EPS ( $n=22)$, no statistical difference could be demonstrated between patients with positive or negative EPS. The presence of an ICD $(p=0.003)$ was associated with LTA events but denoted an already high-risk subgroup and could not be considered a predictive factor.

The Figure 3 shows the time to first LTA event in the following groups: symptomatic at diagnosis (S+); asymptomatic at diagnosis (S-); spontaneous type 1 ECG pattern (ECG+) and drug induced type 1 ECG pattern (ECG-) ( global p-value=0.006).

Following univariate analysis, we divided patients in different groups (Table 3): group S+/ECG+ $(n=14)$; group S+/ECG- $(n=7)$; group S-/ECG+ $(n=22)$ and group S-/ECG$(n=63)$. These four groups showed differences in time to first LTA event (global $p$ value $=0.006$; Figure 4). Group S+/ECG+ had a shorter time to first LTA event compared to group S-/ECG- $(\mathrm{HR}=31$; CI [3.8-265]; $p=0.001)$. No difference was found when making other comparisons. In a second univariate analysis, we divided the spontaneous type 1 ECG pattern group into two groups: type 1 ECG pattern only with fever and other spontaneous type 1 ECG patterns. Whilst there was no difference between them in time to first LTA event $(p=0.08)$ both of these groups showed a shorter time to LTA event compared to the druginduced group ( lobal p-value $=0.002)$. 
Multivariate analyses were adjusted for age and ICD. In a first multivariate analysis, a spontaneous type 1 ECG pattern $(\mathrm{HR}=5.9$; CI $[1.2-30.4] ; p=0.03)$ and symptoms at diagnosis $(\mathrm{HR}=4.7$; CI [1.2-19.4]; $p=0.03)$ were predictive of LTA events.

In a second multivariate analysis of time to first LTA event, a difference was found between the four groups ( global p-value=0.006). Group $\mathrm{S}+\mathrm{ECG}+$ had a shorter time to first LTA event compared to group S-/ECG- (HR=28.9; CI [3.4-242.6]; $p=0.002)$. No difference was found when making other comparisons.

\section{Discussion}

Three of the 8 patients reported in the first description of $\mathrm{BrS}^{1}$ were under 8 years of age. However, few data are available on the natural history in children ${ }^{7,8,11}$ and the management of this special population has been inconsistent ${ }^{12}$. This study represents the largest series of pediatric $\mathrm{BrS}$ patients described as yet. As in the adult population, we show that a spontaneous type 1 ECG pattern and symptoms at diagnosis are predictive of a shorter time to first LTA event.

\section{Brugada syndrome in children}

Our cohort showed no significant gender difference in BrS carriers up to age 15. A trend in male predominance then develops after this age and presumably continues into adulthood. This reflects the likely role of androgens in BrS, which may involve circadian rhythm of testosterone release ${ }^{13,14}$.

More than half of our population was diagnosed during family screening using sodium channel blocker challenge. Recently, Conte et $\mathrm{al}^{8}$ reported their experience of 40 positive sodium channel blocker challenges in children below age 12. During a follow-up of 83 months, only 1 arrhythmic event occurred whereas $10 \%$ of tests were complicated by arrhythmia. In our experience this risk was lower (2/70; 2 NSVT in 2 SCN5A carriers among 
70 tests). Their use at a very young age appears questionable, however, due to the low risk of LTA in asymptomatic patients without a spontaneous type 1 ECG pattern and the potential arrhythmogenic risk and psychological impact of provocation tests ${ }^{15}$.

Fever is known to associate with arrhythmic events ${ }^{16}$ and unmask the type 1 ECG pattern $^{17}$, which is 20 times more common in febrile patients ${ }^{18}$. In this study, fever triggered up to a quarter of all arrhythmic events. Dumaine et $\mathrm{al}^{19}$ have demonstrated a diminished inward current through mutant cardiac sodium channels due to changes in biophysical properties at higher temperatures. Despite this evidence the mechanism of fever-induced $\mathrm{BrS}$ remains incompletely understood. Early childhood might be a period of high risk because of the frequent occurrence of fever. Even if the rate of arrhythmic events during fever is unpredictable we still advise aggressive treatment with antipyretics. We also advise the recording of a standard ECG when BrS children are admitted to hospital with a fever. If the ECG is abnormal, they should be monitored until their ECG returns to its usual baseline.

We chose to include in the same group patients who displayed a type 1 ECG pattern spontaneously or only with fever due to a lack of power resulting from low numbers. These 2 subgroups may not, however, have the same arrhythmic risk and need to be evaluated separately in a larger cohort.

\section{SCN5A mutation status and its implications}

SCN5A mutations were found in a higher proportion of patients than expected. In particular we found a $47 \%$ prevalence of SCN5A mutations in index patients, more than double that seen in adults with $\mathrm{BrS}^{20}$. Given the important role of conduction defects and increasing age in the pathophysiology of the disease $\mathrm{e}^{21,22}$, one can speculate that the impairment of conduction associated with SCN5A mutations facilitates the development of $\mathrm{BrS}$ in the pediatric population. 
All 9 genotyped patients who experienced LTA had a SCN5A mutation, but 7 also displayed a spontaneous type 1 ECG pattern. By contrast, none of the 17 genotype-negative patients, suffered a LTA event. Thus, in our cohort the presence of a SCN5A mutation may be necessary, but is insufficient on its own for the development of LTA $^{23,24}$. These results should, however, be treated cautiously due to the low number of patients and the high prevalence of SCN5A mutations. Further studies are needed to assess if the presence or absence of a $S C N 5 A$ mutation may be useful for risk assessment in the young.

\section{Therapy in the young}

An ICD was implanted in 22 patients with a high subsequent complication rate (41\%). This high risk for adverse events is probably compounded in this young population by rapid physical growth and a high level of physical activity. The incidence may be decreased by using the subcutaneous ICD or subcutaneous coil ${ }^{25}$. In a small and selected group of paediatric patients, Pettit et al. $^{26}$ suggests a lower incidence of inappropriate shocks or reoperations with a subcutaneous ICD compared to a transvenous ICD.

Hydroquinidine may be an attractive alternative, and most of our patients treated with hydroquinidine remained asymptomatic. In the adult population hydroquinidine tends to be a safe alternative $e^{28,29}$ but given the small number of patients and the relatively short follow-up in this cohort, larger-scale studies are needed.

Nonetheless we advise consideration of ICD implantation or quinidine therapy in patients with a spontaneous type 1 ECG pattern and symptoms. The prognosis of the asymptomatic patients as well as patients presented with a drug-induced type 1 ECG pattern seems to be good. Thus those with drug-induced type 1 ECG pattern without symptoms should be only considered for clinical follow-up. There is more uncertainty when symptoms or a spontaneous type 1 ECG pattern are present. Therapy should then be discussed on a case by case basis. Fig. 5 shows a flow-chart of our recommended approach. 


\section{Conclusion}

A spontaneous type 1 ECG pattern and symptoms at diagnosis are predictive of a shorter time to first LTA event in the young. The risk of LTA is especially high in patients with both symptoms and a spontaneous type 1 ECG. These patients need to be considered for ICD implantation and/or chronic therapy with quinidine or hydroquinidine. Patients with a drug-induced type 1 ECG and without symptoms have a low arrhythmic risk and a good prognosis. In this population, regular clinical follow-up without specific treatment seems to be sufficient.

In asymptomatic patients with a spontaneous type 1 ECG pattern and in symptomatic patients without a spontaneous pattern, the risk appears to be relatively low and the decision to eventually implant an ICD or to introduce hydroquinidine therapy needs to be discussed case by case in highly experienced centers. The absence of a SCN5A mutation may then denote a lower risk of events and might be taken into account. Fever remains the most important trigger for LTA events and parents need to be advised to treat it aggressively with anti-pyretics.

\section{Acknowledgements}

This work was supported by NIH grant HL083374 (PJS and LC) and by the Italian Ministry of Health grant GR-2010-2305717 (LC) 


\section{References}

1. Brugada P, Brugada J: Right bundle branch block, persistent ST segment elevation and sudden cardiac death: a distinct clinical and electrocardiographic syndrome. A multicenter report. J Am Coll Cardiol 1992; 20:1391-1396.

2. Probst V, Veltmann C, Eckardt L, et al.: Long-term prognosis of patients diagnosed with Brugada syndrome: Results from the FINGER Brugada Syndrome Registry. Circulation 2010; 121:635-643.

3. Mizusawa Y, Wilde AAM: Brugada syndrome. Circ Arrhythm Electrophysiol 2012; 5:606-616.

4. Crotti L, Marcou CA, Tester DJ, Castelletti S, Giudicessi JR, Torchio M, Medeiros-Domingo A, Simone S, Will ML, Dagradi F, Schwartz PJ, Ackerman MJ: Spectrum and prevalence of mutations involving BrS1- through BrS12-susceptibility genes in a cohort of unrelated patients referred for Brugada syndrome genetic testing: implications for genetic testing. J Am Coll Cardiol 2012; 60:1410-1418.

5. Schwartz PJ, Ackerman MJ, George AL, Wilde AAM: Impact of genetics on the clinical management of channelopathies. J Am Coll Cardiol 2013; 62:169-180.

6. Oe H, Takagi M, Tanaka A, Namba M, Nishibori Y, Nishida Y, Kawarabayashi T, Yoshiyama M, Nishimoto M, Tanaka K, Yoshikawa J: Prevalence and clinical course of the juveniles with Brugada-type ECG in Japanese population. Pacing Clin Electrophysiol PACE 2005; 28:549-554.

7. Probst V, Denjoy I, Meregalli PG, et al.: Clinical aspects and prognosis of Brugada syndrome in children. Circulation 2007; 115:2042-2048.

8. Conte G, Dewals W, Sieira J, et al.: Drug-induced brugada syndrome in children: clinical features, device-based management, and long-term follow-up. J Am Coll Cardiol 2014; 63:2272-2279.

9. Richter S, Sarkozy A, Paparella G, Henkens S, Boussy T, Chierchia G-B, Brugada R, Brugada J, Brugada P: Number of electrocardiogram leads displaying the diagnostic coved-type pattern in Brugada syndrome: a diagnostic consensus criterion to be revised. Eur Heart J 2010; 31:13571364.

10. Priori SG, Wilde AA, Horie M, et al.: HRS/EHRA/APHRS Expert Consensus Statement on the Diagnosis and Management of Patients with Inherited Primary Arrhythmia Syndromes. Heart Rhythm 2013; 10:1932-1963.

11. Conte G, de Asmundis C, Ciconte G, et al: FOllow-up from childhood to adulthood of individuals with family history of brugada syndrome and normal electrocardiograms. JAMA 2014; 312:2039-2041.

12. Harris BU, Miyake CY, Motonaga KS, Dubin AM: Diagnosis and Management of Pediatric Brugada Syndrome: A Survey of Pediatric Electrophysiologists. Pacing Clin Electrophysiol PACE 2014; .

13. Shimizu W, Matsuo K, Kokubo Y, et al.: Sex hormone and gender difference--role of testosterone on male predominance in Brugada syndrome. J Cardiovasc Electrophysiol 2007; 18:415-421. 
14. Yamaki M, Sato N, Okada M, Fujita S, Go K, Sakamoto N, Tanabe Y, Takeuchi T, Kawamura Y, Hasebe $\mathrm{N}$ : A case of Brugada syndrome in which diurnal ECG changes were associated with circadian rhythms of sex hormones. Int Heart J 2009; 50:669-676.

15. Wong LCH, Roses-Noguer F, Till JA, Behr ER: Cardiac evaluation of pediatric relatives in sudden arrhythmic death syndrome: a 2-center experience. Circ Arrhythm Electrophysiol 2014; 7:800806.

16. Amin AS, Meregalli PG, Bardai A, Wilde AAM, Tan HL: Fever increases the risk for cardiac arrest in the Brugada syndrome. Ann Intern Med 2008; 149:216-218.

17. Porres JM, Brugada J, Urbistondo V, García F, Reviejo K, Marco P: Fever unmasking the Brugada syndrome. Pacing Clin Electrophysiol PACE 2002; 25:1646-1648.

18. Adler A, Topaz G, Heller K, Zeltser D, Ohayon T, Rozovski U, Halkin A, Rosso R, Ben-Shachar S, Antzelevitch C, Viskin S: Fever-induced Brugada pattern: How common is it and what does it mean? Heart Rhythm 2013; 10:1375-1382.

19. Dumaine R, Towbin JA, Brugada P, Vatta M, Nesterenko DV, Nesterenko VV, Brugada J, Brugada R, Antzelevitch C: Ionic mechanisms responsible for the electrocardiographic phenotype of the Brugada syndrome are temperature dependent. Circ Res 1999; 85:803-809.

20. Kapplinger JD, Tester DJ, Alders $M$, et al.: An international compendium of mutations in the SCN5A-encoded cardiac sodium channel in patients referred for Brugada syndrome genetic testing. Heart Rhythm 2010; 7:33-46.

21. Nannenberg EA, Sijbrands EJG, Dijksman LM, Alders M, van Tintelen JP, Birnie M, van Langen IM, Wilde AAM: Mortality of inherited arrhythmia syndromes: insight into their natural history. Circ Cardiovasc Genet 2012; 5:183-189.

22. Maury P, Rollin A, Sacher F, et al.: Prevalence and prognostic role of various conduction disturbances in patients with the Brugada syndrome. Am J Cardiol 2013; 112:1384-1389.

23. Bezzina CR, Barc J, Mizusawa Y, et al.: Common variants at SCN5A-SCN10A and HEY2 are associated with Brugada syndrome, a rare disease with high risk of sudden cardiac death. Nat Genet 2013; 45:1044-1049.

24. Sommariva E, Pappone C, Martinelli Boneschi F, Di Resta C, Rosaria Carbone M, Salvi E, Vergara P, Sala S, Cusi D, Ferrari M, Benedetti S: Genetics can contribute to the prognosis of Brugada syndrome: a pilot model for risk stratification. Eur J Hum Genet EJHG 2013; 21:911-917.

25. Tomaske M, Pretre R, Rahn M, Bauersfeld U: Epicardial and pleural lead ICD systems in children and adolescents maintain functionality over 5 years. Europace 2008; 10:1152-1156.

26. Pettit SJ, McLean A, Colquhoun I, Connelly D, McLeod K: Clinical experience of subcutaneous and transvenous implantable cardioverter defibrillators in children and teenagers. Pacing Clin Electrophysiol PACE 2013; 36:1532-1538.

27. Jarman JWE, Lascelles K, Wong T, Markides V, Clague JR, Till J: Clinical experience of entirely subcutaneous implantable cardioverter-defibrillators in children and adults: cause for caution. Eur Heart J 2012; 33:1351-1359. 
28. Belhassen B, Glick A, Viskin S: Efficacy of quinidine in high-risk patients with Brugada syndrome. Circulation 2004; 110:1731-1737.

29. Belhassen B, Glick A, Viskin S: Excellent long-term reproducibility of the electrophysiologic efficacy of quinidine in patients with idiopathic ventricular fibrillation and Brugada syndrome. Pacing Clin Electrophysiol PACE 2009; 32:294-301.

\section{Clinical Perspectives}

This study provides evidence-based indications useful for the cardiologist who may face difficult management decisions when dealing with a Brugada syndrome $(\mathrm{BrS})$ in children. As suspected, a spontaneous type 1 ECG pattern and symptoms at diagnosis are predictive of life-threatening arrhythmia (LTA) events in children affected by BrS. Patients with both are at the high risk and need to be considered for ICD implantation. Asymptomatic patients with a drug-induced type 1 ECG pattern have a good prognosis and regular clinical follow-up seems to be sufficient. Others clinical situations need to be considered on a case by case basis in experienced centers and there may be a role for hydroquinidine as well as aggressive antipyretic therapy. SCN5A negative genotype may be associated with less LTA events, but this remains to be proven. Given the rarity of $\mathrm{BrS}$ in the young, larger studies are required to confirm and then apply these results in daily clinical practice. As undertaken for BrS in adults, specialized centers need to collaborate to evaluate larger cohorts in the future. 


\section{Figures Titles and Legends}

Figure 1: 12-lead ECG at baseline (up) and during a febrile episode (down) in a 2.5 years old female. During fever, ST-segment elevation occurred with coved-type morphology in lead V1 and $\mathrm{V}_{2}$, leading to diagnosis of $\mathrm{BrS}$.

Figure 2: Flow-chart of patients clinical characteristics and events during follow-up.

Figure 3: Kaplan-Meier curves of LTA events during follow-up in four different groups (global p-value $=0.006)$. Patients with spontaneous type 1 ECG pattern $(\mathrm{ECG}+) \mathrm{OR}$ symptoms (S+) at diagnosis had a shorter time to first LTA event.

Figure 4: Kaplan-Meier curves of LTA events during follow-up in four different groups (global p-value $=0.006)$. Patients with spontaneous type 1 ECG pattern $(\mathrm{ECG}+)$ AND symptoms $(\mathrm{S}+)$ at diagnosis had a shorter time to first LTA event.

Figure 5: Flow-chart for management of the young with a known $\mathrm{BrS}$ in the family.

\section{Tables}

Table 1: Patients Characteristics According to their $S C N 5 A$ status $(\mathrm{n}=75)$

\begin{tabular}{|c|c|c|c|}
\hline & Positive $(n=58)$ & Negative $(n=17)$ & p-value \\
\hline Male, n (\%) & $33(57)$ & $10(59)$ & 0.78 \\
\hline Age at diagnosis, $\mathrm{y}$ & $9.8 \pm 6.0$ & $12.7 \pm 4.4$ & 0.02 \\
\hline Symptoms at diagnosis, $\mathrm{n}(\%)$ & $10(17)$ & $3(18)$ & 1 \\
\hline Follow-up, mo & $63[20-102]$ & $66[24-117]$ & 0.70 \\
\hline LTA events during follow-up, n (\%) & $9(16)$ & $0(0)$ & $0,08 *$ \\
\hline Probands, n (\%) & $15(26)$ & $16(94)$ & $<0.0001$ \\
\hline Spontaneous Type 1 ECG Pattern & $20(34)$ & $8(47)$ & 0.40 \\
\hline Familial history of SCD, n (\%) & $25(43)$ & $6(35)$ & 0.78 \\
\hline \multicolumn{4}{|l|}{ Baseline ECG parameters } \\
\hline Heart Rate (bpm) & $83 \pm 23$ & $85 \pm 20$ & 0.06 \\
\hline$P R(m s)$ & $171 \pm 34$ & $155 \pm 20$ & 0.01 \\
\hline$Q R S(m s)$ & $103 \pm 16$ & $94 \pm 14$ & 0.34 \\
\hline QTc Bazett (ms) & $431 \pm 33$ & $402 \pm 34$ & 0.15 \\
\hline Maximum ST Elevation (mm) & $1.8 \pm 2.0$ & $2.7 \pm 2.6$ & 0.03 \\
\hline
\end{tabular}




\begin{tabular}{|l|c|c|c|}
\hline ICD, $\mathrm{n}(\%)$ & $14(24)$ & $3(18)$ & 0.75 \\
\hline Quinidine, $\mathrm{n}(\%)$ & $8(14)$ & $2(12)$ & 0.83 \\
\hline EPS performed, $\mathrm{n}(\%)$ & $14(24)$ & $6(35)$ & 0.47 \\
\hline \multicolumn{1}{|c|}{ positive, $n=20$} & $7(12)$ & $1(6)$ & 0.32 \\
\hline * log-rank p-value & & & \\
\hline
\end{tabular}

Table 2: Patients Characteristics According to LTA Events during Follow-up and Predictive Factors for LTA in Univariate Analysis $(n=106)$

\begin{tabular}{|l|c|c|c|c|}
\hline & LTA events (n=10) & No LTA event (n=96) & HR [CI 95\%] & p-value \\
\hline Male, $n(\%)$ & $6(60)$ & $52(54)$ & $0.79[0.22-2.81]$ & 0.72 \\
\hline Age at diagnosis, y & $6.5 \pm 7.0$ & $11.6 \pm 5.4$ & $0.86[0.76-0.96]$ & $\mathbf{0 . 0 0 9}$ \\
\hline Age at diagnosis <15y, n (\%) & $7(70)$ & $60(62)$ & $0.74[0.19-2.89]$ & 0.66 \\
\hline Follow-up, mo & $42[6-73]$ & $55[15-103]$ & & - \\
\hline Symptoms at diagnosis, $\mathrm{n}(\%)$ & $7(70)$ & $14(15)$ & $9.65[2.481-37.49]$ & $\mathbf{0 . 0 0 1}$ \\
\hline Spontaneous Type 1 ECG Pattern (\%) & $8(80)$ & $28(29)$ & $9.1[1.9-42.96]$ & $\mathbf{0 . 0 0 5}$ \\
\hline Familial history of SCD, n (\%) & $3(30)$ & $43(45)$ & $2.12[0.55-8.21]$ & 0.28 \\
\hline ICD, $\mathrm{n}(\%)$ & $5(50)$ & $17(18)$ & $3.85[1.11-13.36]$ & $\mathbf{0 . 0 0 3}$ \\
\hline SCN5A mutations, $\mathrm{n}(\%)$ & $9(90)$ & $49(51)$ & & $0.08^{*}$ \\
\hline * log-rank p-value & & & & \\
\hline
\end{tabular}


Table 3: Patients Characteristics According to Clinical Presentation and Type 1 ECG $(n=106)$

\begin{tabular}{|c|c|c|c|c|c|}
\hline & $\begin{array}{c}\text { Symptomatic \& } \\
\text { spontaneous }\end{array}$ & $\begin{array}{l}\text { Symptomatic \& } \\
\text { drug induced }\end{array}$ & $\begin{array}{c}\text { Asymptomatic \& } \\
\text { spontaneous }\end{array}$ & $\begin{array}{c}\text { Asymptomatic \& } \\
\text { drug induced }\end{array}$ & p-value \\
\hline & Group $S+/ E+(n=14)$ & Group $S+/ E-(n=7)$ & Group $S-/ E+(n=22)$ & Group S-/E- $(n=63)$ & \\
\hline Male, n (\%) & $10(71)$ & $5(71)$ & $16(73)$ & $27(43)$ & 0.03 \\
\hline Age at diagnosis, $\mathrm{y}$ & $6.0 \pm 5.4$ & $14.3 \pm 5.6$ & $7.5 \pm 5.5$ & $13.1 \pm 4.6$ & $<0.04$ \\
\hline Follow-up, mo & $70[5-125]$ & $91[23-138]$ & $46[8-106]$ & $47[18-93]$ & 0.83 \\
\hline LTA event during follow-up, n (\%) & $6(43)$ & $1(14)$ & $2(9)$ & $1(2)$ & $0.006^{*}$ \\
\hline Familial history of SCD, n (\%) & $2(14)$ & $4(57)$ & $7(32)$ & $33(52)$ & 0.041 \\
\hline \multicolumn{6}{|l|}{ Baseline ECG parameters } \\
\hline Heart Rate (bpm) & $89 \pm 25$ & $66 \pm 13$ & $91 \pm 22$ & $78 \pm 18$ & 0.22 \\
\hline$P R(m s)$ & $176 \pm 25$ & $174 \pm 25$ & $161 \pm 30$ & $162 \pm 33$ & 0.38 \\
\hline$Q R S(m s)$ & $108 \pm 19$ & $99 \pm 19$ & $105 \pm 22$ & $96 \pm 14$ & 0.10 \\
\hline QTc Bazett (ms) & $423 \pm 29$ & $400 \pm 41$ & $423 \pm 29$ & $420 \pm 36$ & 0.48 \\
\hline Maximum ST Elevation ( $\mathrm{mm}$ ) & $3.8 \pm 2.1$ & $1.9 \pm 1.2$ & $3.9 \pm 2.2$ & $0.6 \pm 0.9$ & $<0.001$ \\
\hline $\mathrm{ICD}, \mathrm{n}(\%)$ & $5(36)$ & $3(43)$ & $5(23)$ & $9(14)$ & 0.13 \\
\hline Quinidine, n (\%) & $5(36)$ & 0 & $4(18)$ & $2(3)$ & 0.003 \\
\hline Genetic test performed, n (\%) & $11(79)$ & $2(29)$ & $17(77)$ & $45(71)$ & 0.03 \\
\hline SCN5A mutations, n (\%) & $9(64)$ & $1(14)$ & $11(50)$ & $37(59)$ & 0.15 \\
\hline EPS performed, n (\%) & $7(50)$ & $2(29)$ & $3(14)$ & $10(16)$ & 0.25 \\
\hline positive, $n=22$ & $2(14)$ & $1(14)$ & $1(5)$ & $5(8)$ & 0.91 \\
\hline
\end{tabular}

* p-value calculated by cox model 


\section{Figures}

\section{Figure 1}

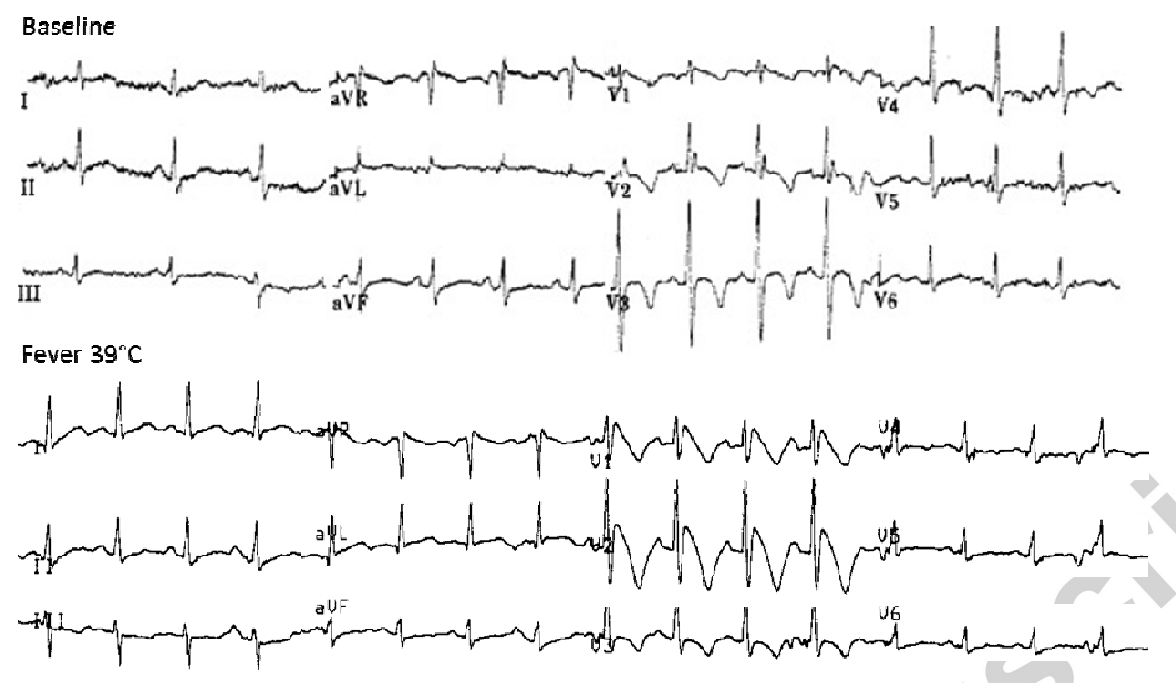




\section{Figure 2}

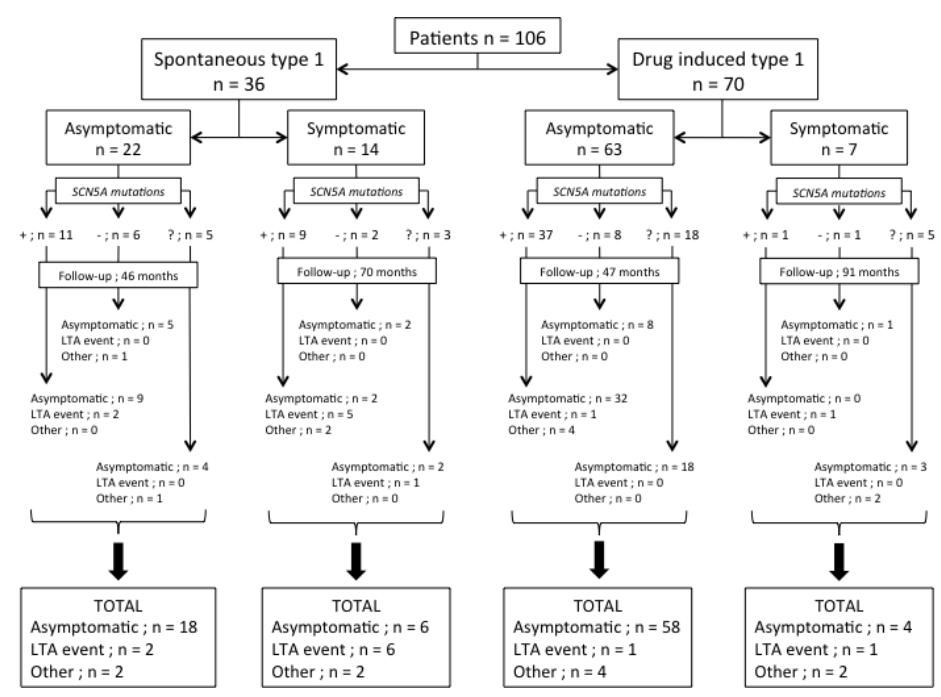


Figure 3

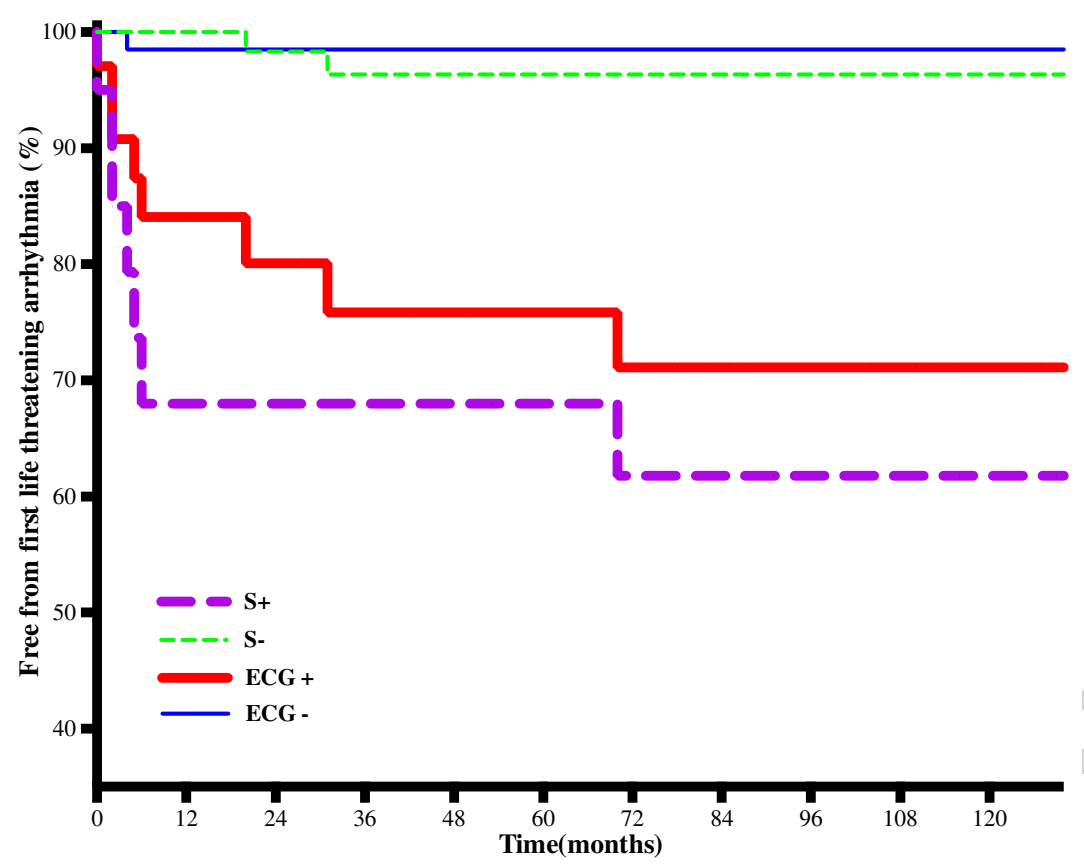




\section{Figure 4}

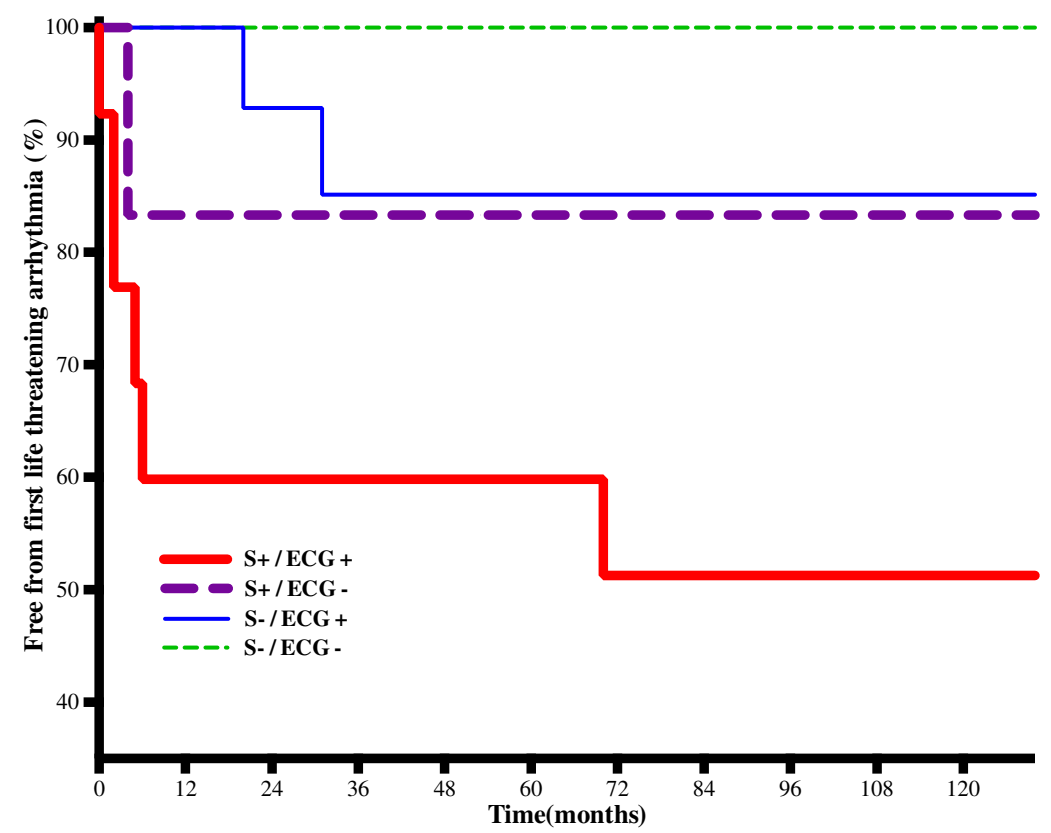

\begin{tabular}{|l|c|c|c|c|c|c|}
\hline months & $\mathbf{0}$ & $\mathbf{1 2}$ & $\mathbf{2 4}$ & $\mathbf{6 0}$ & $\mathbf{9 6}$ & $\mathbf{1 2 0}$ \\
\hline S+/ECG+ = Symptomatic \& Spontaneous Type 1 & 14 & 6 & 6 & 6 & 3 & 2 \\
\hline S+/ECG- = Symptomatic \& Drug induced Type 1 & 7 & 5 & 5 & 4 & 3 & 2 \\
\hline S-/ECG+ = Asymptomatic \& Spontaneous Type 1 & 22 & 22 & 13 & 11 & 6 & 3 \\
\hline S-/ECG- = Asymptomatic \& Drug induced Type 1 & 63 & 63 & 63 & 63 & 63 & 63 \\
\hline
\end{tabular}


Figure 5

* Or earlier review at physician discretion $\uparrow$ Potentially cardiac arrhythmias related symptoms, excluding vaso-vagal syncope $\S$ Ajmaline $1 \mathrm{mg} / \mathrm{Kg}$ or flecaïnide $2 \mathrm{mg} / \mathrm{Kg}$

Lifestyle recommendations, including drug avoidance and fever precautions should be considered for all patients

\section{Spontaneous type 1 ECG pattern}

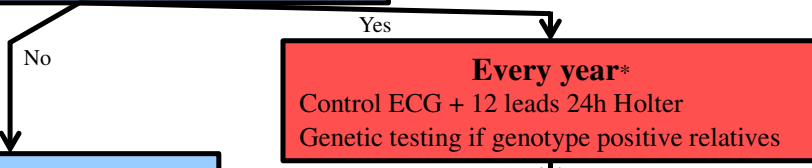

Genetic testing if genotype positive relative

$\checkmark$

\section{Symptoms}

first degree relatives

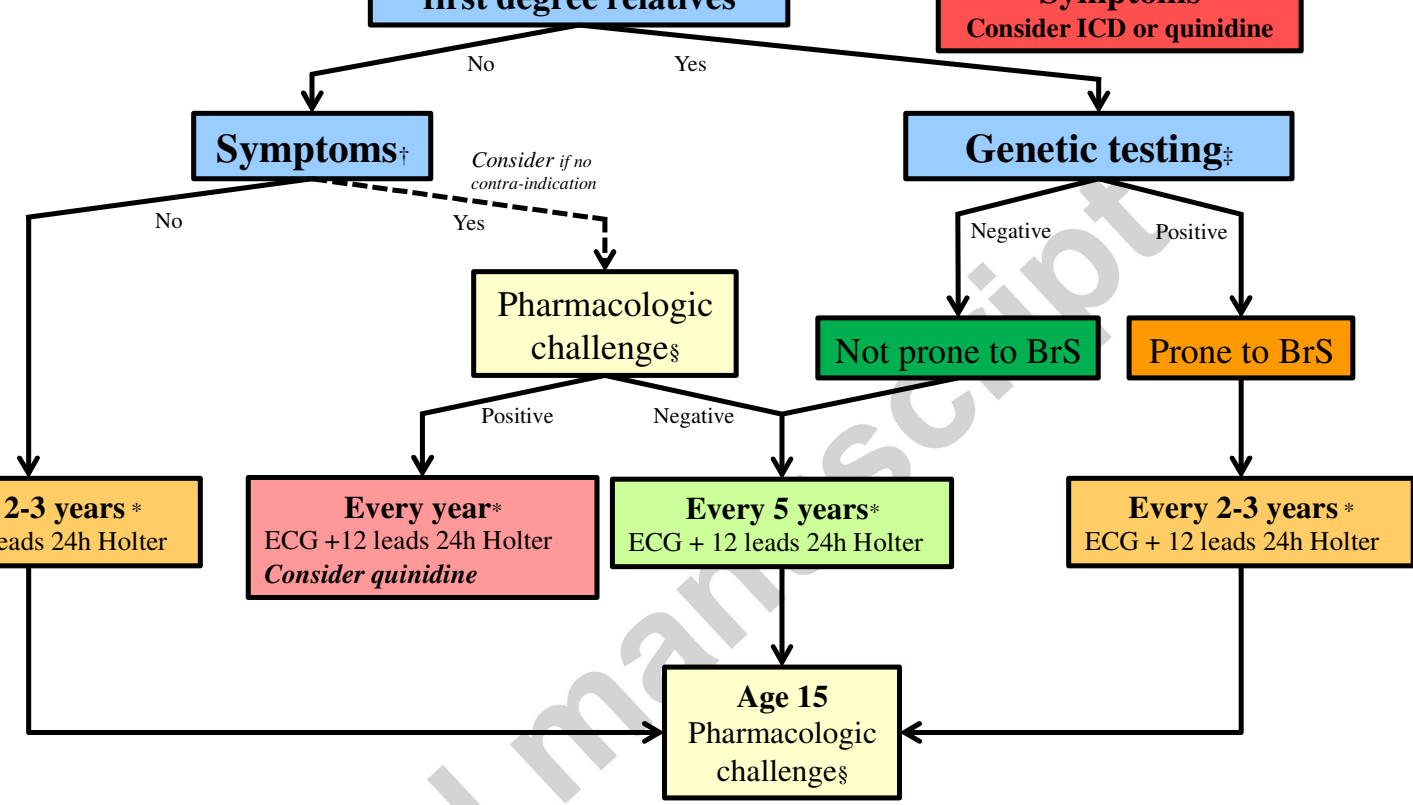

Management of the Young with a known BrS in the Family 